Usages du français et pratiques d'enseignement en Europe balkanique, centrale et orientale - Grèce,

Serbie, Bulgarie, Moldavie, Hongrie, Allemagne, Russie - XVIIIe - XXe siècles

\title{
L'enseignement du français et son histoire dans les manuels de FLE en Grèce : aspects culturels
}

Konstantinos Mytaloulis

\section{OpenEdition}

Journals

Édition électronique

URL : https://journals.openedition.org/dhfles/4247

DOI : $10.4000 /$ dhfles.4247

ISSN : 2221-4038

Éditeur

Société Internationale pour l'Histoire du Français Langue Étrangère ou Seconde

Édition imprimée

Date de publication : 1 juin 2015

Pagination : 208-212

ISSN : 0992-7654

Référence électronique

Konstantinos Mytaloulis, «L'enseignement du français et son histoire dans les manuels de FLE en Grèce : aspects culturels », Documents pour l'histoire du français langue étrangère ou seconde [En ligne], 54 | 2015, mis en ligne le 19 novembre 2017, consulté le 25 mars 2023. URL : http:// journals.openedition.org/dhfles/4247; DOI : https://doi.org/10.4000/dhfles.4247

Ce document a été généré automatiquement le 25 mars 2023

Tous droits réservés 


\title{
L'enseignement du français et son histoire dans les manuels de FLE en Grèce : aspects culturels
}

\author{
Konstantinos Mytaloulis
}

1 Thèse de doctorat en Didactique des langues et des cultures dirigée par Dan Savatovsky, soutenue le 23 janvier 2014, au Centre Bièvre de l'Université Paris 3 Sorbonne-Nouvelle, 503 pages.

2 Cette thèse est le fruit d'une recherche portant sur les manuels de français langue étrangère utilisés en Grèce dans l'enseignement secondaire et primaire, au XIX et à la fin du XXe siècle. Elle se situe dans le domaine de la didactique du FLE et de l'histoire de celle-ci et se propose d'examiner les aspects culturels et interculturels de l'enseignement du FLE.

3 Elle se situe également dans le domaine de la sociolinguistique dont l'objet d'étude est la langue en relation avec des paramètres socio-culturels tels que la société, la classe sociale, l'âge, et intègre d'autres données extralinguistiques, comme la dimension culturelle des dialogues ou de leur péritexte.

4 Son approche est novatrice parce qu'elle met en rapport les événements historiques avec la disciplinarisation du français en Grèce et l'état de la langue française en France à la fin $d u X{ }^{2} I^{e}$ et au début du XIX ${ }^{e}$ siècle avec la conception de l'enseignement du français en Grèce; ensuite, parce qu'elle propose une grille d'évaluation des aspects culturels appelés « points-culture » dans les manuels de FLE.

\section{Structure de la thèse}

5 La $1^{\text {re }}$ partie présente un aperçu historique qui nous aide à comprendre la progression et la diffusion de la langue française depuis Les Serments de Strasbourg jusqu'à l'« Europe française », afin de montrer les raisons pour lesquelles elle est devenue une véritable discipline, non seulement en France mais aussi dans des systèmes éducatifs étrangers, en l'occurrence le grec. 
6 Nous expliquons comment les porteurs de l'érudition française en Grèce et en France ont encouragé et soutenu la francophilie grecque et ont contribué à la disciplinarisation du français langue étrangère, en même temps que se formait le mouvement du philhellénisme européen.

7 Ensuite, nous évoquons le poids des parlers régionaux et les problèmes grammaticaux et orthographiques traités par les linguistes dans l'espace français faisant référence à l'existence de débats similaires en Grèce, entre les partisans de la langue archaïque (la katharévoussa) et les tenants de la langue populaire (le démotique). Le débat sur « quel français enseigner en France? ? à la fin du XvIII ${ }^{\mathrm{e}}$ siècle et au début du XIX dépasse les frontières françaises et s'identifie au débat : «Quel français enseigner en Grèce ? ».

8 Si nous insistons sur la guerre d'indépendance de la Grèce et sur la proclamation de son indépendance c'est pour deux raisons: faire ressortir les conditions politicodiplomatiques dans lesquelles le nouvel État grec apparaît, et esquisser le contexte général dans lequel la connaissance de la langue française fait son apparition dans cette région du monde.

9 La présence du français sur le sol hellénique est consolidée par les écoles françaises tenues par des congrégations religieuses françaises. C'est la raison pour laquelle nous évoquons des établissements qui ont contribué à la diffusion du français depuis la naissance du nouvel État grec jusqu'à nos jours.

10 En marge de cette présentation, nous évoquons l'action de deux personnages historiques importants, Rhigas et Coray qui, en tant que francophiles, ont promu directement ou indirectement l'enseignement du français en Grèce.

11 Dans la $2^{\mathrm{e}}$ partie nous exposons la conception et l'organisation de l'enseignement $\mathrm{du}$ français en Grèce et son introduction dans le cursus scolaire après la naissance de l'État grec en 1830. Nous présentons et commentons également certaines des œuvres littéraires choisies pour l'enseignement du français, en essayant d'expliquer les raisons pour lesquelles le ministère grec a opté pour tel ou tel ouvrage. Viennent s'ajouter, par la suite, des éléments historiques, qui montrent l'influence exercée par la France aux niveaux politique et culturel.

12 Enfin, nous passons à l'analyse des manuels de français utilisés dans les écoles grecques. La présentation détaillée de sept manuels datant du XIX ${ }^{\mathrm{e}}$ siècle ainsi que nos commentaires sur ceux qui ont marqué cette époque, (méthodes Ahn et Ollendorff), apportent des précisions aussi bien sur le contenu que sur la structure des manuels de la période examinée.

13 La $3^{\mathrm{e}}$ partie consacrée au cadre théorique nous donne l'occasion de discuter les notions de culture et civilisation. Avant de poser la question du rapprochement ou non entre langue et culture, nous présentons les points de vue des didacticiens comme F. Cicurel, G. Zarate, M. de Carlo, P. Charaudeau, C. Puren et N. Auger. La clarification de la polysémie des mots culture et de civilisation permet d'introduire notre champ de recherche qu'est le manuel de FLE.

Nous avons jugé important de clore cette partie conceptuelle en fournissant des exemples précis tirés des dialogues des manuels qui attisent la curiosité des apprenants. Nous tentons d'exposer nos premières réflexions sur la tâche interculturelle du professeur de français. Cette partie englobe nos conclusions sur l'image dans les manuels de FLE. 

notre recherche, qui comprend 21 manuels contemporains utilisés dans l'enseignement secondaire et primaire en Grèce sur une période qui s'étend de 1998 à 2009, période charnière marquée, pour ce qui est de l'enseignement des langues, par le CECRL. Nous clarifions les critères de notre choix et la présentation de chaque manuel sous forme de fiche signalétique, suivie de remarques et commentaires. Le recensement des " pointsculture » dispersés dans les manuels de FLE permet de découvrir la régularité de ces points et de les repartir en 27 catégories sur lesquelles s'appuie notre grille.

La $5^{e}$ partie "Dialogues/CECRL » comprend une analyse des dialogues des manuels une analyse placée sous un angle particulier: comment rendre plus clair un acte didactique interculturel des manuels de FLE à travers la culture implicite dans les dialogues qui y figurent? des dialogues dans l'apprentissage des langues étrangères, et nous traitons de la question de savoir comment l'usage de documents authentiques et de dialogues fabriqués marque la pratique pédagogique. Entre ces deux catégories on trouve aussi des dialogues réalistes ou semi-authentiques, dont la nature artificielle ne fait pas obstacle à l'apprentissage, du moment que des deux parties prenantes de l'enseignement, apprenants et enseignants, peuvent prendre conscience de la facticité de ces documents. Les dialogues des manuels cachent des éléments implicites et des paraphrases qui, lorsqu'ils sont repérés, ont des effets positifs, sur l'acquisition des savoirs pour les apprenants.

Nous évoquons les séquences dialoguées de ces dialogues et, suivant J.-M. Adam, nous distinguons séquences phatiques et séquences transactionnelles. Enfin, nous nous posons la question du choc culturel, de la transition douce vers la langue maternelle, enfin du rôle de l'image qui sert à compléter le contenu des dialogues.

Notre bref aperçu historique du Cadre européen commun de référence pour les langues nous permet de suivre son évolution et celle de la perspective actionnelle développée par la «tâche ». Cette partie se termine avec l'organisation en tableaux des " pointsculture " contenus dans les manuels de notre corpus, mis en regard des instructions officielles pour l'apprentissage du FLE et des consignes du CECRL.

Le recensement des points-culture des manuels du corpus et leur catégorisation en rubriques nous a conduit à procéder à la création d'une grille sous forme de tableau ( $6^{\mathrm{e}}$ partie). L'application d'une grille à un manuel de FLE facilite la mise en évidence de la richesse culturelle de celui-ci et de son intérêt pédagogique. Pour la création de notre grille, nous avons pris en compte des grilles existantes ainsi que les rubriques du « niveau-seuil » qui, bien qu'anciennes, peuvent encore servir de référence.

21 La dernière étape de notre travail consiste en l'application de cette grille aux manuels de notre corpus, ce qui nous permet de conclure par une série de remarques.

Cette recherche est donc accompagnée de recommandations didactiques applicables dans un cours de FLE dans l'enseignement secondaire (et primaire) en Grèce : la question de savoir «comment enseigner la langue?» devient alors «comment enseigner la langue par la culture?».

Des thèses comme celle-ci illustrent l'intérêt d'examiner le manuel scolaire comme un objet d'étude. Par le biais des éléments culturels et historiques marquants de son époque, mais aussi révélateurs de la conception du monde que se font ses auteurs, nous 
avons abouti à la constatation que le manuel constitue un monument (au sens de Michel Foucault) du français langue étrangère en tant que discipline, autant qu'un document.

D'ailleurs, l'institutionnalisation de la didactique des langues, son développement en tant que discipline scientifique ne peut se faire indépendamment d'un regard historiographique sur les textes, les manuels et les pratiques qui ont jalonné son évolution. Si l'on veut donner aux enseignants une culture disciplinaire spécifique à leur domaine d'action, l'histoire de l'enseignement des langues (en l'occurrence du FLE) doit devenir un domaine de savoir constitutif de la recherche en didactique des langues et faire partie des programmes de formation des enseignants.

Cela dit, la valeur de cette thèse pour l'historien de l'avenir est qu'elle présente la culture des manuels grecs de FLE depuis le XIX siècle jusqu'à la première décennie du $\mathrm{XXI}^{\mathrm{e}}$ siècle dans leur évolution historique.

\section{AUTEUR}

\section{KONSTANTINOS MYTALOULIS}

Université de Paris 3 Sorbonne-Nouvelle 